\title{
Psychiatric disorders in children and adolescents presenting with unexplained chronic pain: what is the prevalence and clinical relevancy?
}

\author{
Lidewij M. E. Knook - Antoinette Y. Konijnenberg • Joost van der Hoeven • \\ Jan L. L. Kimpen · Jan K. Buitelaar · Herman van Engeland • Elisabeth R. de Graeff-Meeder
}

Received: 5 February 2010/Accepted: 30 October 2010/Published online: 21 December 2010

(C) The Author(s) 2010. This article is published with open access at Springerlink.com

\begin{abstract}
The prevalence of psychiatric disorders among children with unexplained chronic pain (UCP) is high in unselected populations and pain clinics, yet the clinical relevance of these disorders in children referred for unexplained pain is not known. This study assessed the prevalence of clinically relevant psychiatric disorders and their predictors in children referred to a children's hospital for UCP. Psychiatry morbidity was assessed in 134 children, aged 8-17 years, using the Diagnostic Interview Schedule for Children-parent version (DISC-P) and the Semi-structured Clinical Interview for Children and Adolescents (SCICA). Clinical relevance was determined using a maladjustment criterion of 61 or lower on the Children's Global Assessment Scale (CGAS). Pain parameters were measured with standardized questionnaires. Results were analysed by logistic regression. According to the DISC-P, $21 \%$ of the children had clinically relevant psychiatric
\end{abstract}

L. M. E. Knook $(\bowtie) \cdot$ H. van Engeland .

E. R. de Graeff-Meeder

Department of Child and Adolescent Psychiatry, Rudolf Magnus Institute of Neuroscience, University Medical Centre Utrecht, A 01.468 , PO Box 85500,3508 GA Utrecht, The Netherlands e-mail: L.M.E.Knook@umcutrecht.nl

A. Y. Konijnenberg · J. L. L. Kimpen

Department of General Paediatrics, University Medical Centre Utrecht, Utrecht, The Netherlands

J. van der Hoeven

Altrecht, Institute for Mental Health Care, Utrecht,

The Netherlands

\section{J. K. Buitelaar}

Department of Psychiatry and Karakter Centre for Child and Adolescent Psychiatry, Centre for Evidence-based Practice, University Medical Centre Nijmegen, UMC St. Radboud, Nijmegen, The Netherlands disorders, predominantly anxiety disorders (18\%). According to the SCICA, $28 \%$ of the children had clinically relevant psychiatric disorders, consisting of anxiety, affective, and disruptive disorders (12, 19, and 9\%, respectively). Headache (compared to musculoskeletal pain) was an independent clinical predictor of psychiatric morbidity $(\mathrm{OR}=3.10 ; 95 \%$ CI $1.07-8.92, p=0.04$ / adjusted OR 2.99; 95\% CI 1.02-8.74, $p=0.04$ ). In conclusion, clinically relevant psychiatric disorders are common among children and adolescents referred for UCP. Adding a child psychiatrist assessment, treatable affective and disruptive disorders become identifiable. Children with an additional risk are those presenting with headache.

Keywords Chronic pain · Children · Adolescents . Psychiatry

\begin{tabular}{|c|c|}
\hline \multicolumn{2}{|c|}{ Abbreviations } \\
\hline UCP & Unexplained chronic pain \\
\hline DISC & Diagnostic Interview Schedule for Children \\
\hline DISC-C & $\begin{array}{l}\text { Diagnostic Interview Schedule for Children- } \\
\text { Child version }\end{array}$ \\
\hline DISC-P & $\begin{array}{l}\text { Diagnostic Interview Schedule for Children- } \\
\text { Parent version }\end{array}$ \\
\hline SCICA & $\begin{array}{l}\text { Semi-structured Clinical Interview for Children } \\
\text { and Adolescents }\end{array}$ \\
\hline CGAS & Children's Global Assessment Scale \\
\hline SES & omic status \\
\hline OR & Odds \\
\hline CI & Confidence interval \\
\hline DSM-IV & $\begin{array}{l}\text { Diagnostic and Statistical Manual of Mental } \\
\text { Disorders, fourth edition }\end{array}$ \\
\hline PUC & Chronic Pain of Unknown Origin in Children \\
\hline VAS & Visual Analogue Scale \\
\hline
\end{tabular}


PPQ Pediatric Pain Questionnaire

ODD Oppositional Defiant Disorder

ADHD Attention-Deficit Hyperactivity Disorder

\section{Introduction}

Unexplained chronic pain (UCP) in children, i.e. pain of unknown cause lasting 3 months or longer, is a common problem and a challenge to physicians [27]. It is often considered self-limiting and innocuous [33]. However, referred children have impairments in daily life comparable to those seen in individuals with chronic somatic disorders [29]. Moreover, recent population-based and clinical studies have shown that the chronic pain is not self-limiting, despite treatment at specialized clinics [18, 34, 40, 45].

In adults with UCP, pain is associated with depressive and anxiety disorders, and this association is stronger than that observed in healthy controls or in patients with chronic pain of known organic pathology and is still present after correction for bodily symptoms of anxiety and depression $[22,26]$. It is generally recognized that psychosocial factors are involved in childhood UCP, for instance parental distress and maladaptive coping [13, 36, 38, 53, 59], and there is increasing evidence that psychiatric symptoms and psychiatric disorders are also involved [7, 17, 21, 30, 39, $41,46]$. However, current evidence is diverse and does not allow clinically useful generalizations.

Most studies on psychiatric disorders have involved children in community, primary care or tertiary care (specialized pain clinics) samples, which are probably not representative of children with UCP visiting secondary care, like a paediatric outpatient clinic. Moreover, many of the studies of small clinical samples tended to focus on internalizing disorders, whereas psychiatric assessment in children with UCP should also include assessment of externalizing disorders [17]. Another limitation is that different diagnostic measures have been used, mostly based on questionnaires. Relatively few studies have reported on psychiatric disorders assessed by structured clinical psychiatric interviews based on the Diagnostic and Statistical Manual of Mental Disorders, fourth edition (DSM-IV) classification system. In studies in which these interviews were used, methodological shortcomings prevented appropriate estimation of the prevalence of clinically significant psychiatric disorders. First, most psychiatric disorders were assessed with respondent (parent or child)based highly structured interviews and not by clinician assessment of the child. Second, impairment criteria were often not included in structured psychiatric interviews. When paediatricians encounter patients with UCP with psychiatric symptoms, they may request psychiatric assessment, because these symptoms may be distressing and treatment might improve pain and functioning, even if the symptoms are not associated with impairment, directly. However, when a child psychiatrist diagnoses psychopathology by the means of DSM-IV classification system, impairment, in addition to duration, is a key criterion for determining whether the psychopathology is clinically significant and need any treatment. In the general population, the prevalence of child psychiatric disorders decreases considerably when impairment is included [8]. Therefore, although there are varieties of literature about psychopathology in children with UCP, little is known about its prevalence and clinical significance in referred children and whether psychiatrists should be involved in the diagnostic work-up.

In adults with medically unexplained symptoms, cognitive behavioural therapy is the only evidence-based treatment thus far found to reduce physical symptoms, psychological distress, and disability [15, 52]. In children, general guidelines for the assessment and treatment of UCP advocate combination of psychological, physical, and pharmacological treatment [3, 27, 37], and evidence for a cognitive behavioural approach becomes apparent [9, 12, 14, 43]. Treatment results, however, are often limited to pain control, with little evidence for effect on mood and disability [14]. On the other hand, there is strong evidence for psychological and pharmacological treatment of child psychiatric disorders. Proper identification of children with UCP at risk of psychiatric disorders is therefore required, because it justifies referral for psychiatric assessment and care. Moreover, the risk of repeated unproductive medical investigation and intervention might decrease [2, 31, 51].

The aims of our study were to estimate the prevalence of clinically relevant psychiatric disorders in children and adolescents visiting a secondary care paediatric outpatient clinic, using both parent responses to a diagnostic interview and an interview with the child by a child psychiatrist. Second, we investigated whether demographic parameters (age, sex, and socioeconomic status) and pain parameters (severity, duration, and location) are predictors of psychiatric disorders in children referred for UCP.

\section{Method}

Setting, participants, and recruitment

The Pain of Unknown origin in Children study (PUC study) was conducted in the Wilhelmina Children's Hospital, University Medical Centre Utrecht, The Netherlands, between January 2000 and July 2002. Children 
who were referred to the outpatient clinic were eligible if they met the following criteria: age between 8 and 18 years; pain for at least 3 months prior to the visit and without an explanatory diagnosis made by the referring doctor; first visit to the out-patient clinic for this symptom; and sufficient knowledge of Dutch. The Dutch healthcare system is organized such that a general practitioner first evaluates a child. If further specialized care is necessary the child can be referred to a regional or a university hospital. If specialists in the regional hospital need a second opinion, children can be referred to a university hospital. In the Netherlands, therefore, a university hospital to some extent covers the same population as a regional clinic. Our clinic is organized such that $\sim 50 \%$ of the general paediatric outpatient population and $\sim 15 \%$ of the other paediatric departments consist of children who are evaluated only by a general practitioner before referral. Children with musculoskeletal pain, abdominal pain, and headache were recruited mainly from the department of general paediatrics, but also from the departments of paediatric neurology, orthopaedics, immunology, rheumatology, and gastroenterology. The three selected pain locations resemble the most frequent reported types of chronic pain in children and adolescents [44] thereby covering most of the chronic pain population in children and adolescents. Each child was evaluated according to standard practice. Immediately after the first visit, the child and its parents were invited to participate in the study. After informed consent was given, additional research data were gathered. All study assessments were performed during the routine diagnostic work-up. The study protocol was approved by the Medical Ethics Committee of the University Medical Centre Utrecht.

The original study on Chronic Pain of Unknown origin in Children (PUC) was primarily focused on improving insight in the diagnostic process of general paediatricians encountering children referred for UCP. On the subject of psychiatric disorders the research question was if clinical characteristics or standardized questionnaires help to accurately diagnose psychiatric morbidity. For this purpose a child and adolescent psychiatrist, based on child SCICA outcome, DISC outcome, and/or a combination of both, made a psychiatric diagnosis. Second, the psychiatric DISC and SCICA data facilitated us to explore new hypotheses from a psychiatric point of view.

In total, 149 children were included. Fifteen children withdrew their consent because of lack of time and motivation ( 2 male and 6 female), or unwillingness to have a psychiatric assessment ( 1 male and 6 female), leaving 134 children (37 male and 97 female).
Assessments

\section{Psychiatric disorder}

The Diagnostic Interview Schedule for Children (DISC) and the Clinical Interview for Children and Adolescents (SCICA) were used to assess the presence of psychiatric disorders. The DISC is a highly structured respondentbased interview for children [50]. It assesses 34 different child- and adolescent psychiatric diagnoses according to DSM-IV diagnostic criteria. The child version of the DISC$\mathrm{C}$ is only reliable in children aged 12 years and older [48]. Since our study group consisted of children between 8 and 18 , we used the parent version of the DISC. The interviews were conducted by three trained lay-interviewers who followed the guidelines of the DISC manual. The Semistructured Clinical Interview for Children and Adolescents (SCICA) mimics clinical interviewing and observation by child psychiatrists [19]. One experienced child psychiatrist $(\mathrm{JvdH})$, who received extensive training in using this method, conducted the SCICA and was blinded to other information about the child. SCICA data were converted into 6 DSM-IV-based scales (affective problems, anxiety problems, somatic problems, attention-deficit hyperactivity problems, oppositional defiant problems, and conduct problems). We used clinical $\mathrm{T}$ scores of 55 or higher as cutoff, indicating a clear diagnosis as advocated by McConaughy [35]. Since all our participants had chronic pain, we excluded the somatic problems category as an indication for psychiatric disorder. Child and parent interviews were conducted simultaneously in separate rooms, shortly after intake and before completion of the standard diagnostic work-up (routine care).

\section{Clinical relevance of psychiatric diagnosis}

The Children's Global Assessment Scale (CGAS) is a clinician scored scale of adaptive functioning that has good psychometric properties useful for incorporating a measure of impairment in the classification of childhood psychiatric disorders [4, 5, 49]. It is an adaptation of the Global Assessment Scale developed for adults. The CGAS has 10 anchor points which all contain behaviourally oriented descriptions that depict behaviours and life situations applicable to children. Scores on the CGAS range from 100 (no impairment) to 0 (severe impairment). A score of 61 is the best cut-off for definite psychiatric cases, identifying children who have received mental health services [5]. A positive score on one or more DSM-IV scales combined with a CGAS lower than 61 was considered a clinically relevant psychiatric disorder. 


\section{Sociodemographic factors}

Sex, age, and socioeconomic status (SES) were assessed. SES was categorized according to the Dutch Standard Classification of Occupations, based on the father's occupation [54].

Pain

Children scored their pain on the Visual Analogue Scale (VAS) of the Varni/Thompson Pediatric Pain Questionnaire (PPQ) [55]. The PPQ-VAS assesses present pain and worst pain intensity for the previous week. Each VAS is a $10-\mathrm{cm}$ horizontal line with no numbers, marks, or descriptive vocabulary words along the length of the line. The VAS is anchored with the pain descriptors "not hurting, no discomfort, no pain" at one end, and "hurting a whole lot, very uncomfortable, severe pain" at the other end. Subsequent research studies have supported the measurement properties of the PPQ-VAS in school-aged children [10, 23, 24, 47, 56, 57]. Pain location was determined from the medical history and was categorized into three groups: musculoskeletal pain, abdominal pain, and headache, resembling the most frequent reported types of pain in children and adolescents [44]. Pain duration is expressed in months, from onset of pain to the day of assessment.

\section{Statistical analysis}

To assess statistical differences in pain location subgroups chi-quadrate analysis was used for proportional variables. Kruskal-Wallis one-way analyses of variance was used to assess age-differences in the three pain location groups. Spearman correlation was used to assess correlation between age and specific psychiatric diagnosis (anxiety disorder, affective disorder, and disruptive disorder). Univariate logistic regression analysis was performed to assess independent predictors of psychiatric morbidity. Results are expressed as odds ratios with corresponding $95 \%$ confidence intervals. Adjusted odds ratios were calculated using the same logistic model by adding possible confounding factors as covariates (age and gender of the child). For statistical analyses the Statistical Package for Social Sciences (SPSS, Inc, Chicago, Illinois, USA) version 17.0 was used. Statistical significance was considered for $p$ values $\leq 0.05$.

\section{Results}

Patient characteristics are shown in Table 1. There were no age differences in the three pain location groups. Tables 2 and 3 show the proportion of children with clinically
Table 1 Patient characteristics $(n=134)$

\begin{tabular}{ll}
\hline Demographics & \\
Sex (\% girls) & 72.4 \\
Age in years, median (range) & $12(8-17)$ \\
SES father, $n(\%)(n=128)$ & \\
$\quad$ Low & $31(24.2)$ \\
Middle & $54(42.2)$ \\
High & $43(33.6)$ \\
Pain & \\
Duration of pain in months, median (range) & $12(3-144)$ \\
VAS Current pain, mean (SD), $n=130$ & $4.5(3.1)$ \\
VAS Pain previous days, mean (SD), $n=129$ & $7.1(2.8)$ \\
Location, $n(\%)^{\mathrm{a}}$ & \\
Musculoskeletal & $60(44.8)$ \\
Abdominal & $43(32.1)$ \\
Headache & $31(23.1)$ \\
\hline
\end{tabular}

${ }^{a}$ Location of pain at presentation

relevant psychiatric disorders $(\mathrm{CGAS}<61)$ and their psychiatric diagnosis, as assessed by parental interview (DISC, $n=134$ ) and child psychiatric assessment (SCICA $n=131$ ) distributed by pain location. Based on the parental interview, $40 \%$ of the children had a psychiatric disorder, but only $21 \%$ had a psychiatric disorder that was clinically relevant. The predominant disorder was anxiety disorder (specific phobias $10 \%$, separation anxiety disorders $7 \%$, social phobias $4 \%$, and generalized anxiety disorders $4 \%$ ), which affected $18 \%$ of the children. Five percent of the children were diagnosed with an affective disorder, mainly depressive disorders (4.5\%), and 5\% were diagnosed with disruptive disorder, namely, oppositional defiant disorder (ODD; 4\%) and attention-deficit/hyperactivity disorder (ADHD; 3\%). Based on the child psychiatric assessment (SCICA), $53 \%$ of the children had a psychiatric disorder, but only $29 \%$ had a clinically relevant disorder. According to this assessment, $12 \%$ of the children had an anxiety disorder, 19\% an affective disorder, and $9 \%$ a disruptive disorder.

Figure 1 shows the proportion of children identified as psychiatric cases by DISC and/or SCICA assessment. Of the 131 children assessed by both interviews, $14.5 \%$ of the children had a psychiatric diagnosis according to both DISC-P and SCICA outcome. In addition to the DISC who identified $20.5 \%$ of the children as psychiatric case, the SCICA identified another $14.5 \%$. As much as $35 \%$ of the children had clinically relevant psychiatric disorder assessed by one or both interviews. The various single and comorbid psychiatric cases, based on the DISC-P (28 patients) and SCICA (38 patients), are given in Table 4.

Correlation analysis between age and specific psychiatric disorder (anxiety disorder, affective disorder, and 
Table 2 Prevalence of clinically relevant psychiatric disorder: parental interview (DISC-P) by pain location, $n(\%)$

\begin{tabular}{|c|c|c|c|c|c|}
\hline & \multicolumn{5}{|l|}{ DISC-P } \\
\hline & Total $(n=134)$ & $\mathrm{MP}(n=60)$ & $\mathrm{AP}(n=43)$ & $\mathrm{HA}(n=31)$ & $p$-value \\
\hline Psychiatric disorder & $28(20.9)$ & $8(13.3)$ & $10(23.3)$ & $10(32.3)$ & 0.098 \\
\hline PD no impairment ${ }^{\mathrm{a}}$ & $53(39.6)$ & $21(35.0)$ & $18(41.9)$ & $14(45.2)$ & 0.599 \\
\hline Anxiety disorder & $24(17.9)$ & 7 (11.7) & 8 (18.6) & $9(29.0)$ & 0.122 \\
\hline Affective disorder & $7(5.2)$ & $2(3.3)$ & $3(7.0)$ & $2(6.5)$ & $*$ \\
\hline Disruptive disorder $^{\mathrm{b}}$ & $7(5.2)$ & $3(5.0)$ & $2(4.7)$ & $2(6.5)$ & $*$ \\
\hline
\end{tabular}

One or more psychiatric disorder per patient and CGAS $<61$

$M P$ musculoskeletal pain, $A P$ abdominal pain, $H A$ headache

* Conditions for chi-quadrate analysis not met

${ }^{\text {a }}$ Psychiatric disorder without impairment criterion

b ADHD, ODD, Conduct Disorder

Table 3 Prevalence of clinically relevant psychiatric disorder: child psychiatrists' assessment (SCICA) by pain location, $n$ (\%)

\begin{tabular}{|c|c|c|c|c|c|}
\hline & \multicolumn{5}{|l|}{ SCICA } \\
\hline & Total $(n=131)$ & $\mathrm{MP}(n=58)$ & $\mathrm{AP}(n=43)$ & HA $(n=30)$ & $p$ value \\
\hline Psychiatric disorder & $38(29.0)$ & $11(19.0)$ & $15(34.9)$ & $12(40.0)$ & 0.07 \\
\hline PD no impairment ${ }^{\mathrm{a}}$ & $69(52.6)$ & $23(39.7)$ & $28(65.1)$ & $18(60.0)$ & 0.027 \\
\hline Anxiety disorder & $16(12.2)$ & $4(6.9)$ & $6(14.0)$ & $6(20.0)$ & $*$ \\
\hline Affective disorder & $25(19.1)$ & $7(12.1)$ & $11(25.6)$ & $7(23.3)$ & 0.185 \\
\hline Disruptive disorder ${ }^{\mathrm{b}}$ & $12(9.2)$ & $4(6.9)$ & $3(7.0)$ & $5(16.7)$ & $*$ \\
\hline
\end{tabular}

One or more psychiatric disorder per patient and CGAS $<61$

$M P$ musculoskeletal pain, $A P$ abdominal pain, $H A$ headache

* Conditions for chi-quadrate analysis not met

${ }^{a}$ Psychiatric disorder without impairment criterion

b ADHD, ODD, Conduct Disorder

disruptive disorder) revealed only a significant negative relation between age and disruptive disorder assessed by both DISC-P $\left(r_{\mathrm{s}}-0.149, p=0.043\right)$ and SCICA $\left(r_{\mathrm{s}}-\right.$ $0.200, p=0.011)$. This implies that with increasing age less disruptive disorders were diagnosed. Table 5 presents the predictors of clinical psychiatric disorder (yes/no), assessed with the DISC-P. Headache as main location of pain was a significant predictor of a clinical psychiatric diagnosis $(\mathrm{OR}=3.10 ; 95 \%$ CI $1.07-8.92, p=0.04)$. Pain duration showed a significant association with psychiatric diagnosis assessed by the DISC-P (OR $=1.014 ; 95 \% \mathrm{CI}$ $1.000-1.028, p=0.054, \mathrm{OR}_{\mathrm{adj}}=1.015$; $95 \%$ CI $1.001-$ $1.030, p=0.036$ ). Table 6 presents the predictors of clinical psychiatric disorder (yes/no), assessed with the child psychiatrist (SCICA). Again, headache was a significant predictor of clinical psychiatric disorder $(\mathrm{OR}=2.85 ; 95 \%$ CI 1.07-7.61, $p=0.04)$. Age, sex, SES, and other pain parameters were not predictive of clinical psychiatric disorders.

\section{Discussion}

Our study is the first to systematically investigate the prevalence of clinically significant psychiatric disorders in children with UCP referred to a children's hospital. We found that psychiatric morbidity is common in children and adolescents with UCP referred to a children's hospital. Combining a parental psychiatric interview with an interview with the child by a child psychiatrist and using an impairment criterion for clinical relevancy, $35 \%$ of the children with UCP were found to suffer from psychiatric disorder. Using a standardized psychiatric interview for parents (DISC-P) in combination with an impairment criterion, we found an overall prevalence of psychiatric disorder of $21 \%$. This prevalence is three times higher than that among healthy Dutch adolescents assessed with the same instrument and impairment criterion [58], and is also higher than the prevalence of psychiatric disorder, assessed with the same instrument, in children attending paediatric 


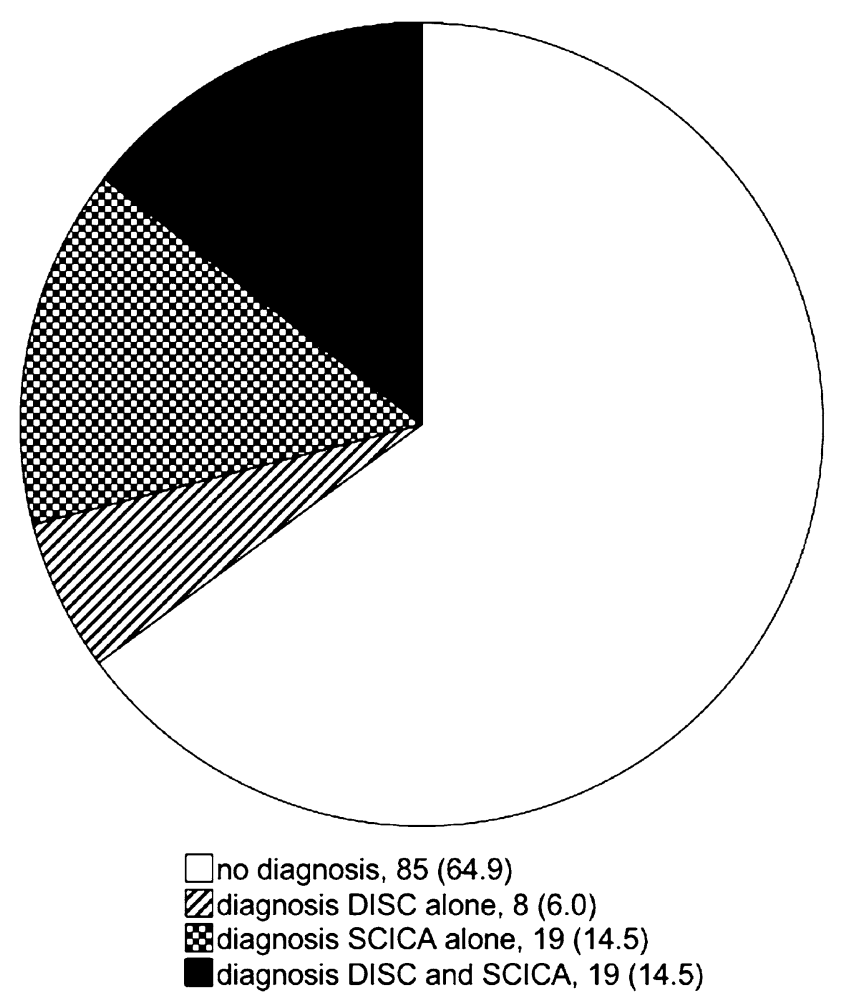

Fig. 1 Psychiatric cases identified by parental interview (DISC) and/ or child psychiatrists' assessment (SCICA)

Table 4 Single and comorbid psychiatric cases by parental interview (DISC) and child psychiatrists' assessment (SCICA), $n(\%)$

\begin{tabular}{lcc}
\hline & $\begin{array}{l}\text { Parental } \\
\text { interview }\end{array}$ & $\begin{array}{c}\text { Child psychiatrist } \\
\text { assessment }\end{array}$ \\
\hline Single & $20(71.4)$ & $23(60.5)$ \\
AnxD & $17(61.7)$ & $6(15.8)$ \\
AffD & $2(7.1)$ & $12(31.6)$ \\
DisD & $1(3.6)$ & $5(13.2)$ \\
Comorbid & $8(28.6)$ & $15(39.5)$ \\
AnxD and AffD & $2(7.1)$ & $8(21.1)$ \\
AnxD and DisD & $3(10.7)$ & $2(5.3)$ \\
AffD and DisD & $1(3.6)$ & $5(13.2)$ \\
AnxD and AffD and DisD & $2(7.1)$ & $0(0)$ \\
Total & $28(100)$ & $38(100)$ \\
\hline
\end{tabular}

$\overline{A n x D}$ anxiety disorder, $A f f D$ affective disorder, $D i s D$ disruptive disorder

primary care [11]. The high prevalence rate in our study group is in line with previous population studies of psychiatric morbidity in children with UCP $[16,17]$ and studies performed in pain clinic [41] and primary care [7] settings.

The prevalence of psychiatric disorders was higher (28\%) when a child psychiatrist interviewed the child
(SCICA). Furthermore, there was a discrepancy between symptoms reported by parents and the child psychiatrist assessment. More children reported depressive and disruptive disorders, while parents reported more anxiety symptoms. Concerning the identification of psychiatric cases, more cases were identified using one informant (parent or child), than using both. In addition to the parent version of the DISC, the SCICA even resulted in an extra $15 \%$ identification of children suffering from psychiatric disorder. Our results are in line with previous studies showing little overlap between subjects with child DSM diagnoses identified by parent report and child self-report $[1,20,58]$. Furthermore, including observation of child psychiatric symptoms in the SCICA may result in distinctive information in the diagnostic process. A clinical child psychiatric assessment would thus seem to be of additional importance for diagnosing psychiatric disorders in children referred for UCP. When incorporating structured interviews in the diagnostic work-up of children with UCP, adding a SCICA to the parent version of the DISC considerably helps to identify children suffering from psychiatric disorders. Our results further show that in research on psychopathology in children with UCP, combining structured parent and child diagnostic interviews helps to determine reasonable prevalence of various psychiatric disorders.

Internalizing disorders are common comorbid disorders in children across the life span and have been explained by a common diathesis and genetic background [6]. The higher prevalence of depressive disorders based on the child psychiatrist assessment is in contrast with the study of Garber et al., which showed that mothers tended to report more depressive symptoms than did their children with recurrent abdominal pain [21]. Other research, however, has shown that girls, particularly as they grow older, report higher levels of depressive symptoms than do their mothers [28]. The presence of disruptive disorders, in our study ADHD and ODD, is in line with the population-based finding that disruptive disorders are part of the psychopathology associated with UCP [17]. The relatively low parent-rated prevalence of disruptive disorder (ADHD and ODD) was unexpected, because parent report is considered more valuable than child report for diagnosing symptoms of ADHD [32]. The mean age of the children was 12 years, an age at which children can be expected to reliably describe their behaviour and interference with daily activities, and this may explain why child report and observation by the child psychiatrist resulted in a higher prevalence of clinically relevant disruptive disorders than did diagnosis based on parent report.

To our knowledge this is the first study in children and adolescents with UCP showing that headache is distinctively predicting clinical psychiatric disorder. Compared to 
Table 5 Predictors of psychiatric disorder based on parent report (DISC-P)

${ }^{a}$ Adjusted for age and sex

Table 6 Predictors of psychiatric disorder based on child psychiatrists' assessment (SCICA) a Adjusted for age and sex
OR $(95 \% \mathrm{CI})$

$p$ value

$\mathrm{OR} \operatorname{adj}^{\mathrm{a}}(95 \% \mathrm{CI})$

$p$ value

\begin{tabular}{|c|c|c|c|c|}
\hline \multicolumn{5}{|l|}{ Demographics } \\
\hline \multicolumn{5}{|l|}{ Sex } \\
\hline Girls & Reference & & & \\
\hline Boys & $1.062(0.421-2.677)$ & 0.898 & & \\
\hline Mean age in years & $0.884(0.748-1.046)$ & 0.152 & & \\
\hline \multicolumn{5}{|l|}{ SES } \\
\hline Low & $1.314(0.442-3.906)$ & 0.623 & & \\
\hline Middle & $0.756(0.271-2.107)$ & 0.592 & & \\
\hline High & Reference & & & \\
\hline \multicolumn{5}{|l|}{ Pain } \\
\hline Duration of pain & $1.014(1.000-1.028)$ & 0.054 & $1.015(1.001-1.030)$ & 0.036 \\
\hline VAS (0-10) & & & & \\
\hline Current pain & $1.058(0.921-1.217)$ & 0.425 & $1.090(0.939-1.265)$ & 0.256 \\
\hline Pain previous days & $1.037(0.886-1.214)$ & 0.65 & $1.059(0.897-1.249)$ & 0.5 \\
\hline \multicolumn{5}{|l|}{ Location } \\
\hline Musculoskeletal & Reference & - & Reference & - \\
\hline Abdominal & $1.970(0.705-5.500)$ & 0.196 & $1.786(0.629-5.069)$ & 0.276 \\
\hline Headache & $3.095(1.074-8.924)$ & 0.036 & $2.993(1.024-8.743)$ & 0.045 \\
\hline
\end{tabular}

\begin{tabular}{|c|c|c|c|c|}
\hline & OR $(95 \% \mathrm{CI})$ & $p$ value & OR $\operatorname{adj}^{\mathrm{a}}(95 \% \mathrm{CI})$ & $p$ value \\
\hline \multicolumn{5}{|l|}{ Demographics } \\
\hline \multicolumn{5}{|l|}{ Sex } \\
\hline Girls & Reference & & & \\
\hline Boys & $0.920(0.392-2.158)$ & 0.849 & & \\
\hline Mean age in years & $0.964(0.833-1.116)$ & 0.622 & & \\
\hline \multicolumn{5}{|l|}{ SES } \\
\hline Low & $2.466(0.913-6.662)$ & 0.075 & & \\
\hline Middle & $0.655(0.248-1.734)$ & 0.395 & & \\
\hline High & Reference & & & \\
\hline \multicolumn{5}{|l|}{ Pain } \\
\hline $\begin{array}{l}\text { Duration of pain } \\
\text { VAS }(0-10)\end{array}$ & $1.005(0.991-1.018)$ & 0.477 & $1.006(0.992-1.020)$ & 0.414 \\
\hline Current pain & $1.109(0.974-1.263)$ & 0.119 & $1.125(0.981-1.291)$ & 0.092 \\
\hline Pain previous days & $1.013(0.881-1.165)$ & 0.854 & $1.012(0.875-1.170)$ & 0.871 \\
\hline \multicolumn{5}{|l|}{ Location } \\
\hline Musculoskeletal & Reference & - & Reference & - \\
\hline Abdominal & $2.289(0.923-5.674)$ & 0.074 & $2.235(0.888-5.622)$ & 0.088 \\
\hline Headache & $2.848(1.067-7.606)$ & 0.037 & $2.859(1.064-7.681)$ & 0.037 \\
\hline
\end{tabular}

musculoskeletal pain, children referred for unexplained chronic headache had a 3-times higher risk of having an additional psychiatric disorder. Although not significant, possibly due to a lack of power, abdominal pain tended to predict psychiatric disorder assessed by a child psychiatrist. Egger also showed that pain location sites are associated with specific psychiatric disorders [16, 17]. In this context, a previous study, on pain location in adults with chronic pain referred for psychiatric consultation, is also worthy of note. This study showed that patients with headache and abdominal pain were more likely to have anxiety, somatosensory amplification, and somatoform disorders, whereas musculoskeletal pain patients showed stronger counter dependency traits [25]. Furthermore, the combination of headache and abdominal pain is the most reported combination of pain locations in children and adolescents with chronic pain [44], and children with persistent pain more often suffer from headache compared to other pain 
locations [45]. Therefore, although an abundance of research hypothesizes common aetiology in chronic pain conditions, distinct subgroups within the chronic pain population possibly exist. Future research, however, is needed to elaborate the role of pain location in psychopathology of children with UCP. For pediatric practice, our results imply that for children with unexplained pain located in their head in particular, psychiatric work up is warranted.

Our findings should be interpreted in the context of several limitations. Focus on pain as presenting complaint may have led to recall of less psychiatric symptoms, inducing a lower prevalence of psychiatric disorder. Absence of teacher-report questionnaires and a psychiatric assessment on pervasive developmental disorder and personality disorders might also result in missing common psychiatric disorders in our sample. The broad age range in our sample limits generalizability for clinical practice with children and adolescents with UCP. A sample with exclusively adolescents with UCP, for example, would possibly have resulted in higher prevalence of depressive disorder. However, analyses in our sample did not reveal relation between age and prevalence of psychiatric disorder in general, anxiety disorder, and affective disorder. The significant inverse relation between age and disruptive disorder cases we found implies that a sample without adolescents might have resulted in higher prevalence of disruptive disorder. The fact that the child psychiatrist was aware of the study hypothesis might have introduced bias, with the psychiatrist making more psychiatric diagnoses. Nevertheless, we tried to ensure that these diagnoses were clinically relevant by using an impairment criterion, which resulted in a much lower prevalence of psychiatric diagnoses. We do not know whether the 15 children who refused to participate in the psychiatric assessment suffered from psychiatric morbidity, and therefore cannot estimate whether their withdrawal introduced bias. However, this group did not differ clinically from other non-participants, and therefore we do not think the non-response biased our results.

The high prevalence of clinically relevant psychiatric disorders in this referred sample with UCP has implications for diagnosis and treatment in daily clinical practice. When a child presents with UCP, it is essential to make a careful psychiatric assessment, including a professional child observation and interview, symptom severity, and impairment. If psychiatric disorders are present, evidence-based child psychiatric treatment should be offered. Although research on the effect of treatment of psychiatric disorders on UCP in children is lacking, there is evidence from adults to show that treatment of depression has a beneficial effect on the associated chronic pain [42,60]. Because children with UCP frequently experience limitations and impairments in their daily activities, which interfere with their development, any physical, psychological, or psychiatric treatment able to reduce this interference should be incorporated in a tailored treatment plan.

\section{Conclusion}

We found that psychiatric assessment of children referred for UCP often revealed treatable psychiatric disorders. Child psychiatrist's ratings of child-reported symptoms and behavioural observation make an important contribution to the identification of specific psychiatric disorders. Children presenting with headache are particularly at risk.

Acknowledgments All residents and consulting physicians of the Wilhelmina Children's Hospital are gratefully acknowledged for assistance with patient recruitment.

Conflict of interest The authors declare that they have no conflict of interest.

Open Access This article is distributed under the terms of the Creative Commons Attribution Noncommercial License which permits any noncommercial use, distribution, and reproduction in any medium, provided the original author(s) and source are credited.

\section{References}

1. Angold A, Weissman MM, John K, Merikangas KR, Prusoff BA, Wickramaratne P, Gammon GD, Warner V (1987) Parent and child reports of depressive symptoms in children at low and high risk of depression. J Child Psychol Psychiatry 28:901-915

2. Barsky AJ, Orav EJ, Bates DW (2005) Somatization increases medical utilization and costs independent of psychiatric and medical comorbidity. Arch Gen Psychiatry 62:903-910

3. Berger MY, Gieteling MJ, Benninga MA (2007) Chronic abdominal pain in children. BMJ 334:997-1002

4. Bird HR, Canino G, Rubio-Stipec M, Ribera JC (1987) Further measures of the psychometric properties of the Children's Global Assessment Scale. Arch Gen Psychiatry 44:821-824

5. Bird HR, Yager TJ, Staghezza B, Gould MS, Canino G, RubioStipec M (1990) Impairment in the epidemiological measurement of childhood psychopathology in the community. J Am Acad Child Adolesc Psychiatry 29:796-803

6. Bittner A, Egger HL, Erkanli A, Jane CE, Foley DL, Angold A (2007) What do childhood anxiety disorders predict? J Child Psychol Psychiatry 48:1174-1183

7. Campo JV, Bridge J, Ehmann M, Altman S, Lucas A, Birmaher B, Di LC, Iyengar S, Brent DA (2004) Recurrent abdominal pain, anxiety, and depression in primary care. Pediatrics 113:817-824

8. Canino G, Shrout PE, Rubio-Stipec M, Bird HR, Bravo M, Ramirez R, Chavez L, Alegria M, Bauermeister JJ, Hohmann A, Ribera J, Garcia P, Martinez-Taboas A (2004) The DSM-IV rates of child and adolescent disorders in Puerto Rico: prevalence, correlates, service use, and the effects of impairment. Arch Gen Psychiatry 61:85-93

9. Christie D, Wilson C (2005) CBT in paediatric and adolescent health settings: a review of practice-based evidence. Pediatr Rehabil 8:241-247 
10. Clancy CA, McGrath PJ, Oddson BE (2005) Pain in children and adolescents with spina bifida. Dev Med Child Neurol 47:27-34

11. Costello EJ, Edelbrock C, Costello AJ, Dulcan MK, Burns BJ, Brent D (1988) Psychopathology in pediatric primary care: the new hidden morbidity. Pediatrics 82:415-424

12. Eccleston C, Malleson PN, Clinch J, Connell H, Sourbut C (2003) Chronic pain in adolescents: evaluation of a programme of interdisciplinary cognitive behaviour therapy. Arch Dis Child $88: 881-885$

13. Eccleston C, Crombez G, Scotford A, Clinch J, Connell H (2004) Adolescent chronic pain: patterns and predictors of emotional distress in adolescents with chronic pain and their parents. Pain 108:221-229

14. Eccleston C, Palermo TM, Williams AC, Lewandowski A, Morley S (2009) Psychological therapies for the management of chronic and recurrent pain in children and adolescents. Cochrane Database Syst Rev:CD003968

15. Eccleston C, Williams AC, Morley S (2009) Psychological therapies for the management of chronic pain (excluding headache) in adults. Cochrane Database Syst Rev:CD007407

16. Egger HL, Angold A, Costello EJ (1998) Headaches and psychopathology in children and adolescents. J Am Acad Child Adolesc Psychiatry 37:951-958

17. Egger HL, Costello EJ, Erkanli A, Angold A (1999) Somatic complaints and psychopathology in children and adolescents: stomach aches, musculoskeletal pains, and headaches. J Am Acad Child Adolesc Psychiatry 38:852-860

18. El-Metwally A, Halder S, Thompson D, Macfarlane GJ, Jones GT (2007) Predictors of abdominal pain in schoolchildren: a 4year population-based prospective study. Arch Dis Child 92:1094-1098

19. Ferdinand RF, Hoogerheide KN, Van Der EJ, Visser JH, Koot HM, Kasius MC, Verhulst FC (2003) The role of the clinician: three-year predictive value of parents', teachers' and clinicians' judgment of childhood psychopathology. J Child Psychol Psychiatry 44:867-876

20. Foley D, Rutter M, Pickles A, Angold A, Maes H, Silberg J, Eaves L (2004) Informant disagreement for separation anxiety disorder. J Am Acad Child Adolesc Psychiatry 43:452-460

21. Garber J, Zeman J, Walker LS (1990) Recurrent abdominal pain in children: psychiatric diagnoses and parental psychopathology. J Am Acad Child Adolesc Psychiatry 29:648-656

22. Garcia-Cebrian A, Gandhi P, Demyttenaere K, Peveler R (2006) The association of depression and painful physical symptoms-a review of the European literature. Eur Psychiatry 21:379-388

23. Gragg RA, Rapoff MA, Danovsky MB, Lindsley CB, Varni JW, Waldron SA, Bernstein BH (1996) Assessing chronic musculoskeletal pain associated with rheumatic disease: further validation of the pediatric pain questionnaire. J Pediatr Psychol 21:237-250

24. Graumlich SE, Powers SW, Byars KC, Schwarber LA, Mitchell MJ, Kalinyak KA (2001) Multidimensional assessment of pain in pediatric sickle cell disease. J Pediatr Psychol 26:203-214

25. Gregory RJ, Manring J, Berry SL (2000) Pain location and psychological characteristics of patients with chronic pain. Psychosomatics 41:216-220

26. Henningsen P, Zimmermann T, Sattel H (2003) Medically unexplained physical symptoms, anxiety, and depression: a metaanalytic review. Psychosom Med 65:528-533

27. Howard RF (2003) Current status of pain management in children. JAMA 290:2464-2469

28. Kiss E, Gentzler AM, George C, Kapornai K, Tamas Z, Kovacs M, Vetro A (2007) Factors influencing mother-child reports of depressive symptoms and agreement among clinically referred depressed youngsters in Hungary. J Affect Disord 100:143-151

29. Konijnenberg AY, Uiterwaal CS, Kimpen JL, Van der HJ, Buitelaar JK, de Graeff-Meeder ER (2005) Children with unexplained chronic pain: substantial impairment in everyday life. Arch Dis Child 90:680-686

30. Konijnenberg AY, de Graeff-Meeder ER, van der HJ, Kimpen JL, Buitelaar JK, Uiterwaal CS (2006) Psychiatric morbidity in children with medically unexplained chronic pain: diagnosis from the pediatrician's perspective. Pediatrics 117:889-897

31. Lindley KJ, Glaser D, Milla PJ (2005) Consumerism in healthcare can be detrimental to child health: lessons from children with functional abdominal pain. Arch Dis Child 90:335-337

32. Loeber R, Green SM, Lahey BB, Stouthamer-Loeber M (1991) Differences and similarities between children, mothers, and teachers as informants on disruptive child behavior. J Abnorm Child Psychol 19:75-95

33. Malleson PN, Connell H, Bennett SM, Eccleston C (2001) Chronic musculoskeletal and other idiopathic pain syndromes. Arch Dis Child 84:189-192

34. Martin AL, McGrath PA, Brown SC, Katz J (2007) Children with chronic pain: impact of sex and age on long-term outcomes. Pain 128:13-19

35. McConaughy SH, Achenbach TM (2001) Manual for the Semistructured Clinical Interview for Children and Adolescents, 2nd edn. University of Vermont, Research Center for Children, Youth, \& Families, Burlington, VT

36. Merlijn VP, Hunfeld JA, van der Wouden JC, HazebroekKampschreur AA, Koes BW, Passchier J (2003) Psychosocial factors associated with chronic pain in adolescents. Pain 101:33-43

37. Merlijn VP, Hunfeld JA, van der Wouden JC, HazebroekKampschreur AA, van Suijlekom-Smit LW, Koes BW, Passchier J (2005) A cognitive-behavioural program for adolescents with chronic pain-a pilot study. Patient Educ Couns 59:126-134

38. Merlijn VP, Hunfeld JA, van der Wouden JC, HazebroekKampschreur AA, Passchier J, Koes BW (2006) Factors related to the quality of life in adolescents with chronic pain. Clin J Pain 22:306-315

39. Mikkelsson M, Sourander A, Piha J, Salminen JJ (1997) Psychiatric symptoms in preadolescents with musculoskeletal pain and fibromyalgia. Pediatrics 100:220-227

40. Mirovsky Y, Jakim I, Halperin N, Lev L (2002) Non-specific back pain in children and adolescents: a prospective study until maturity. J Pediatr Orthop B 11:275-278

41. Mongini F, Rota E, Deregibus A, Ferrero L, Migliaretti G, Cavallo F, Mongini T, Novello A (2006) Accompanying symptoms and psychiatric comorbidity in migraine and tension-type headache patients. J Psychosom Res 61:447-451

42. Muller N, Schennach R, Riedel M, Moller HJ (2008) Duloxetine in the treatment of major psychiatric and neuropathic disorders. Expert Rev Neurother 8:527-536

43. Palermo TM, Wilson AC, Peters M, Lewandowski A, Somhegyi H (2009) Randomized controlled trial of an Internet-delivered family cognitive-behavioral therapy intervention for children and adolescents with chronic pain. Pain 146:205-213

44. Perquin CW, Hazebroek-Kampschreur AA, Hunfeld JA, Bohnen AM, van Suijlekom-Smit LW, Passchier J, van der Wouden JC (2000) Pain in children and adolescents: a common experience. Pain 87:51-58

45. Perquin CW, Hunfeld JA, Hazebroek-Kampschreur AA, van Suijlekom-Smit LW, Passchier J, Koes BW, van der Wouden JC (2003) The natural course of chronic benign pain in childhood and adolescence: a two-year population-based follow-up study. Eur J Pain 7:551-559

46. Powers SW, Gilman DK, Hershey AD (2006) Headache and psychological functioning in children and adolescents. Headache 46:1404-1415

47. Sawyer MG, Whitham JN, Roberton DM, Taplin JE, Varni JW, Baghurst PA (2004) The relationship between health-related 
quality of life, pain and coping strategies in juvenile idiopathic arthritis. Rheumatology (Oxford) 43:325-330

48. Schwab-Stone M, Fallon T, Briggs M, Crowther B (1994) Reliability of diagnostic reporting for children aged 6-11 years: a test-retest study of the Diagnostic Interview Schedule for Children-Revised. Am J Psychiatry 151:1048-1054

49. Shaffer D, Gould MS, Brasic J, Ambrosini P, Fisher P, Bird H, Aluwahlia S (1983) A children's global assessment scale (CGAS). Arch Gen Psychiatry 40:1228-1231

50. Shaffer D, Fisher P, Lucas CP, Dulcan MK, Schwab-Stone ME (2000) NIMH Diagnostic Interview Schedule for Children Version IV (NIMH DISC-IV): description, differences from previous versions, and reliability of some common diagnoses. J Am Acad Child Adolesc Psychiatry 39:28-38

51. Sharpe M, Carson A (2001) "Unexplained" somatic symptoms, functional syndromes, and somatization: do we need a paradigm shift? Ann Intern Med 134:926-930

52. Speckens AE, van Hemert AM, Spinhoven P, Hawton KE, Bolk JH, Rooijmans HG (1995) Cognitive behavioural therapy for medically unexplained physical symptoms: a randomised controlled trial. BMJ 311:1328-1332

53. Stanford EA, Chambers CT, Biesanz JC, Chen E (2008) The frequency, trajectories and predictors of adolescent recurrent pain: a population-based approach. Pain 138:11-21
54. Statistics Netherlands (1992) Standaard Beroepenclassificatie (Dutch Standard Classification of Occupations). Voorburg, Heerlen

55. Varni J, Thompson K (1985) The Varni/Thompson Pediatric Pain Questionnaire (unpublished manuscript)

56. Varni JW, Thompson KL, Hanson V (1987) The Varni/Thompson Pediatric Pain Questionnaire. I. Chronic musculoskeletal pain in juvenile rheumatoid arthritis. Pain 28:27-38

57. Varni JW, Rapoff MA, Waldron SA, Gragg RA, Bernstein BH, Lindsley CB (1996) Effects of perceived stress on pediatric chronic pain. J Behav Med 19:515-528

58. Verhulst FC, Van Der EJ, Ferdinand RF, Kasius MC (1997) The prevalence of DSM-III-R diagnoses in a national sample of Dutch adolescents. Arch Gen Psychiatry 54:329-336

59. Walker LS, Baber KF, Garber J, Smith CA (2008) A typology of pain coping strategies in pediatric patients with chronic abdominal pain. Pain 137:266-275

60. Wise TN, Fishbain DA, Holder-Perkins V (2007) Painful physical symptoms in depression: a clinical challenge. Pain Med 8(Suppl 2):S75-S82 